\section{Intelligence in injury prevention: artificial and otherwise}

\author{
Roderick J McClure
}

In its modern form, injury prevention is about 60 years old. ${ }^{12}$ For all of this time injury prevention has been a leader in the field of academic public health. Injury prevention has led the way in multidisciplinary and transdisciplinary thinking, has been an early adopter of technologies supporting the data revolution and has pioneered the development of implementation science to achieve population-level improvements.

In the 1960s, Haddon was explicitly linking the principles of engineering to those of epidemiology, in defining kinetic energy as the causal agent of injury (which he recommended be managed using a host-agent-environment/primarysecondary-tertiary prevention model). ${ }^{3}$ In the 1980s, authors in the USA were describing trauma deaths as a system performance issue, ${ }^{4}$ and in the 1990 s the Swedish Government was articulating a systems solution to the escalating problem of road crash injury. ${ }^{5}$ With its foundations in injury surveillance and frequent use of routinely collected administrative data for injury-specific purposes, modern injury prevention was quick to incorporate ideas from the developing field of data science for data linkage, ${ }^{6}$ narrative text mining $^{7}$ and data visualisation. ${ }^{8}$ Evidence of the development of implementation epidemiology in injury prevention is readily available, ${ }^{9}$ but best illustrated in the dramatic reduction in road crash deaths in highincome countries from the 1970s.

Arguably, this leadership has been driven by fortunate necessity. From the beginning injury prevention researchers have needed to go where many health fields are now only just starting to tread. Engineering, psychological and social sciences are implicit in the causal models that explain injury as a medical outcome. The nature of injury prevention frames problems in a way that encourages health researchers to push the boundaries of medical model thinking and traditional health research methods. The quotidian public presence

Correspondence to Dr Roderick J McClure, School of Rural Medicine, University of New England, Armidale, NSW 2351, Australia; rmcclure@une.edu.au of injury ensures research is coproduced with the public and focused on implementation usefulness.

A signature benefit of the needs-based incentive for scientific innovation is the efficiency of natural selection. Innovations are not pursued because they are bright and shiny but because they provide practical solutions to problems. A new technology without a purpose, like academic vanity, is quickly passed over in the search for something of real use. It is a simple approach: define the problem; set the research question; choose the scientific tool you need to help you answer the question. If the right tool does not existinvent one that does the task required.

In this issue we have two manuscripts exploring the performance of new artificial intelligence (AI)-based applications to specific challenges in the field of injury prevention. The first examines the use of text mining to facilitate the screening and selection phase when conducting systematic reviews. ${ }^{10}$ The second takes the essential epidemiological variable 'place' and proposes a more sophisticated method for case-control study matching using satellite imagery and machine learning. ${ }^{11}$

The authors of both the two manuscripts approached the new technologies with 'usefulness' being their prime consideration. The manuscripts represent careful and considered integration of classic approaches with new technologies that enable more efficient ${ }^{10}$ or more sophisticated $^{11}$ categorisation. Each achieves a novel enhancement of the 'old' epidemiological method. Importantly, each contributes to the collective understanding of concepts, principles and practices that comprise the new methodological applications. The authors' explanation of their use of AI in real-world examples helps create confidence in what sometimes can appear to be a 'black box process' and shows how you can link artefactual correlations with conceptual meanings.

In this first issue for 2020, I would like to take the opportunity to thank those members of our editorial team who finished their term at the end of last year, and welcome our new editors to the board. Thank you to all reviewers who have served such a critical role, and all of you who have submitted manuscripts to the journal for review.

In this first issue of 2020, with the decade stretching ahead of us, let us remember the role of innovation, and keep striving to lead from the front.

Funding The authors have not declared a specific grant for this research from any funding agency in the public, commercial or not-for-profit sectors.

Competing interests None declared.

Patient consent for publication Not required.

Provenance and peer review Not commissioned; internally peer reviewed.

(C) Author(s) (or their employer(s)) 2020. No commercial re-use. See rights and permissions. Published by BMJ.

\section{(D) Check for updates}

To cite McClure RJ. Inj Prev 2020;26:1.

Inj Prev 2020;26:1.

doi:10.1136/injuryprev-2020-043642

\section{ORCID iD}

Roderick J McClure http://orcid.org/0000-0002-90678282

\section{REFERENCES}

1 Gordon JE. The epidemiology of accidents. Am J Public Health Nations Health 1949;39:504-15.

2 Haddon W, Suchman EA, Klein D. Accident research methods and approaches. New York: Harper and Rowe, 1964.

3 Haddon WEnergy damage and 10 countermeasure strategies. J Trauma Inj Infect Crit Care 1973;13:321-31.

4 West JG, Trunkey DD, Lim RC. Systems of trauma care. A study of two counties. Arch Surg 1979;114:455-60.

5 Tingvall C. The Zero Vision. A road transport system free from serious health losses. In: Holst von $\mathrm{H}$, Nygren $\AA$., Thord R, eds. Transportation, traffic safety and health. Berlin: Springer Verlag, 1997: 37-57.

6 Cameron CM, Purdie DM, Kliewer EV, et al. Population health and clinical data linkage: the importance of a population registry. Aust N Z J Public Health 2007;31:459-63.

7 McKenzie K, Scott DA, Campbell MA, et al. The use of narrative text for injury surveillance research: a systematic review. Accid Anal Prev 2010;42:354-63.

8 Martinez R, Ordunez P, Soliz PN, et al. Data visualisation in surveillance for injury prevention and control: conceptual bases and case studies. Injury Prevention 2016;22:i27-33.

9 McClure RJ, Davey TM. Implementation epidemiology: the frequency distribution and determinants of effective practice. Afr Saf Prom J 2013;11:3-12.

10 Giummarra MJ, Lau G, Gabbe BJ. Evaluation of text mining to reduce screening workload for injuryfocused systematic reviews. Inj Prev 2020;26:55-60.

11 Jay J. Alcohol outlets and firearm violence: a placebased case-control study using satellite imagery and machine learning. Inj Prev 2020;26:61-6. 